\title{
Subjective Well Being in Older Adults: Current State and Gaps of Research
}

\author{
Dieter Ferring and Thomas Boll \\ University of Luxembourg
}

This is an authors' preprint which differs somewhat from the final book chapter that appeared as:

Ferring, D., \& Boll, T. (2010). Subjective well-being in older adults: Current state and gaps of research. In L. Bovenberg, A. van Soest, \& A. Zaidi (Eds.), Ageing, health, and pensions in Europe (pp. 173-205). Houndmills, Basingstoke, Hampshire: Palgrave Macmillan. 


\section{Policy questions}

Subjective well being (SWB) refers to an evaluation of an individual's life from his or her own perspective. It contrasts sharply with evaluations made from the point of view of external observers (researchers or policymakers), which are based on objective criteria related to health, education, income or other aspects (Diener, 2006). Recently, prominent SWB researchers have argued forcefully in favour of supplementing traditional objective indicators of well being or quality of life (such as economic indicators) with indicators of SWB (thus, people's evaluations and feelings about their lives). This should provide the public and politicians with more complete and relevant information for public discussion and political decision-making (see Diener, Kesebir and Lucas, 2008). In our opinion, these arguments apply with equal measure to the quality of life and SWB of older adults. The following list is an overview of policy questions about these issues. The list comprises five sets of questions that will in part be answered in later sections of the chapter:

- Level, variation and developmental course of SWB: What is the average level of SWB in older adults (compared to other age groups), and how does SWB vary between and within older adults in the course of their life?

- Sources of SWB: Which life circumstances contribute to SWB of older adults? Is there a demand to remove SWB-decreasing living conditions of older people by policy measures? (Such measures could involve local, regional, national or supranational levels of policymaking).

- Effects of SWB: To what extent does high SWB of older adults produce positive individual and societal outcomes (such as good health, high work performance, high community involvement)?

- Value issues about SWB: Should policymaking aim to reach or keep a certain level of SWB, or to increase SWB, in older adults?

- Promoting SWB: What are the possibilities, the limits, and the effects of policy measures (referring to pensions, support services, opportunities for lifelong learning) in influencing SWB of older citizens?

The next section presents some answers to the policy questions on the basis of existing research, and highlights where further research is needed to give satisfactory answers.

\section{Major progress in understanding}

This section is comprised of five subsections: the first three provide a conceptual clarification of the term SWB, followed by a discussion of measurement issues. Subsequently, we 
highlight the structure of SWB and the theoretical status of the concept in causal networks. On the basis of these explanations, the fourth subsection presents the main findings on the developmental course, on the causes and consequences of SWB in older adults and on what relevant interventions might involve. This is followed by a fifth subsection discussing models of SWB regulation in older adults.

\subsection{Conceptual clarification and measurement issues}

As mentioned above, SWB refers to an evaluation of an individual's life from his or her own perspective, which contrasts with evaluations made from the point of view of external observers (including researchers and policymakers), which are based on objective criteria. Leading researchers agree that SWB has a cognitive component (namely, the evaluation of one's life) and an affective component (namely, the presence of positive- and absence of negative feelings) (Diener, 2006). This consensus is also shared by prominent researchers of SWB in late life (Diener and Suh, 1998; Ferring et al., 2004; Pinquart and Sörensen, 2000; Staudinger, 2000). SWB can refer broadly to one's life as a whole or more narrowly to specific life domains (that is, health, material wealth, social relationships). This difference in scope has been considered particularly with respect to the cognitive component of SWB by distinguishing between global 'life satisfaction' (LS) and 'domain satisfaction' (DS).

Most empirical studies on SWB of older adults have relied on self-reports (obtained in questionnaires or interviews) as measures of SWB. The cognitive components of SWB (life satisfaction) have been assessed by

(1) single-item measures ('How do you feel about your life as a whole?' followed by a rating scale of satisfaction/ dissatisfaction; see Andrews and Withey, 1976),

(2) direct multiple-item measures of global life satisfaction (Satisfaction with Life Scale by Diener, Emmons, Larsen and Griffin, 1985), or

(3) global life-satisfaction indices, as aggregated scores over several domain-specific satisfaction ratings (Personal Well-Being Index; Cummins et al., 2003).

The affective components of SWB have been assessed by either single-item measures (see Andrews and Withey, 1976) or multiple-item scales of affect (see Affect Balance Scale by Bradburn, 1969; Positive And Negative Affect Scale, PANAS by Watson, Clark and Tellegen, 1988). Table 1 provides a classification of the SWB measures. Even though SWB has a cognitive and an affective component, the measurement in many existing studies has focused on just one of them-that is, life satisfaction (often global life satisfaction assessed by just one item) or positive/negative affect. A domain-specific measure of positive or negative affect has-to the best of our knowledge-not been realised yet, and this represents an important taskfor further research. 
Table 1: Classification of common SWB measures

\begin{tabular}{|l|l|l|}
\hline \multirow{2}{*}{ Type of variable } & \multicolumn{2}{|c|}{ Focus } \\
& One's life as a whole & Specific areas of one's life \\
\hline Cognitive evaluation & $\begin{array}{l}\text { Global life satisfaction } \\
\text { (e.g., Life Satisfaction Index) }\end{array}$ & $\begin{array}{l}\text { Domain satisfaction (e.g., } \\
\text { ratings of satisfaction with } \\
\text { one's health) }\end{array}$ \\
\hline Positive affect & $\begin{array}{l}\text { Global positive affect } \\
\text { (e.g., positive subscale of } \\
\text { Affect Balance Scale) }\end{array}$ & $\begin{array}{l}\text { Domain-specific positive } \\
\text { affect }\end{array}$ \\
\hline Negative affect & $\begin{array}{l}\text { Global negative affect } \\
\text { (e.g., negative subscale of } \\
\text { Affect Balance Scale) }\end{array}$ & $\begin{array}{l}\text { Domain-specific negative } \\
\text { affect }\end{array}$ \\
\hline
\end{tabular}

Kahneman and colleagues have proposed alternative approaches to replace global self-reports of life satisfaction: The Experience Sampling Method (ESM) and Daily Reconstruction Method (DRM; Kahneman et al., 2004). The ESM requires that subjects use an electronic diary that beeps at random times and asks respondents to indicate the intensity of positive and negative feelings in everyday life. DRM requires that respondents fill out a diary about events of their previous day and ascertain how they felt during each event on selected affect dimensions. To the best of our knowledge, these methods have not yet been applied in studies on SWB in later life.

Only a few studies have examined the equivalence of SWB measures across age groups, which is a precondition for a meaningful interpretation of possible mean differences between such groups. Here, measurement equivalence refers to the extent to which a given measure of SWB has identical relations to the theoretical construct of SWB in different age groups. Existing studies have examined this for the cognitive or the affective component of SWB, or for both components. Results have been mixed, indicating that measures were (see Lawrence and Liang, 1988) or were not (see Pons et al., 2000) equivalent.

Self-report measures pose specific challenges for old and very old individuals, if they suffer from cognitive impairments and/ or language disturbances: To what extent are they able to comprehend the survey questions appropriately and to give meaningful answers? Moreover, at what degree of cognitive impairment do they lose their ability to do so? In that case, what other avenues exist for assessing subjective-not objective-well being? Several instruments have been developed for persons suffering from dementia, in which data had to be provided by the individuals themselves and/or by other informants (thus, family members 
or professional caregivers). Problems with using such instruments have been extensively discussed. The current state of the art can be described as follows (Roick et al., 2007):

(1) From a gerontological and ethical point of view, one should not abstain from collecting self-reports of SWB;

(2) Measurement of SWB through self-report is possible in older adults with mild- and even moderate degrees of dementia;

(3) Measures can be designed in a way that facilitates participation despite cognitive impairments (thus, face-to-face administration by trained interviewers, simplified item wording and response formats; see Logsdon et al., 2002);

(4) Consensus between self-reports of SWB and reports provided by other persons (including family members, caregivers) is rather low. Other persons systematically report a lower level of SWB than older adults report, themselves;

(5) Reports of SWB by family members or caregivers are systematically influenced by attributes of the person reporting (for example, caregiver burden, depression, attitudes toward dementia);

(6) Less biased ratings may be provided by independent observers who-in contrast to family members or caregivers-should not be motivated to distort their judgements in a positive or negative direction.

The prevalence prognosis of dementia shows a clear rise with age. ${ }^{1}$ The development of suitable measurement tools for the subjective- and the observer perspective represents an important task for the future-in order to develop a broad understanding of the psychosocial aspects of these diseases (see section 3.1).

\subsection{Structure of SWB}

Psychologists and economists have conducted several studies on the structure of SWB. In so doing, they refer mostly to the relations between the cognitive subcomponents of SWB: the relation between domain satisfaction (DS) and global life satisfaction (LS). These links have been theoretically conceived in two different ways (see Schimmack, 2008). The 'bottom-up' approach assumes that global LS depends on DS (thus, satisfaction with a limited set of life domains, including health, job, financial situation, family life, friendships). In contrast, the 'top-down' approach assumes that the various measures of DS depend on

\footnotetext{
${ }^{1}$ According to estimations by Ferri et al. (2005), the number of people with dementia over the age of 60 in the Western European region will increase from 4.9 million in 2001 to 9.9 million in 2040. The increase will be from 1 to 3.2 million for the Eastern European regions, respectively.
} 
global LS. These two models have different implications: 'Bottom-up' approaches predict that changes in DS (such as financial satisfaction) produce changes in global LS, whereas 'topdown' approaches predict that changes in DS will not produce changes in LS. The current evidence from the psychological literature favours more the 'bottom-up' approach (Schimmack, 2008).

Recent studies by economists based on data from very large and approximately representative samples across all adult age groups (German Socio-Economic Panel; United States General Social Survey) have provided further evidence for the 'bottom-up' approach. First, LS can be successfully predicted from a set of DS at a certain point of time: LS turned out to be most strongly related to financial satisfaction, health satisfaction and job satisfaction, but most weakly related to house satisfaction and environmental satisfaction (van Praag et al., 2003). Second, the average trend in LS across the life cycle can be successfully predicted from average life-cycle trends of four DS (satisfaction with family life, financial situation, job and health; see Easterlin, 2006). Third, differences between men and women in the life-cycle trend of LS correspond to the male-female differences in the life-cycle trends in satisfaction with two domains: 'Early in adult life, women are more satisfied than men with their family life and finances and correspondingly happier .... In late life men feel better about their family and financial circumstances and are the happier of the two' (Plagnol and Easterlin, 2008, p. 609). Fourth, the functional relation of LS to educational level (positive curve) and to year of assessment (fairly flat curve) can be predicted clearly from the relationship of four DS (family life, financial, job and health satisfaction) to education and to year of assessment (Easterlin and Sawangfa, 2007).

An additional advantage of this domain approach is that it can be easily supplemented with assumptions about objective characteristics of the domains that may produce changes in DS (an increase in income produces an increase of financial satisfaction, decreasing health accompanies diminishing health satisfaction, and so forth). Following this approach, van Praag et al. (2003) found significant and in part specific relations between socioeconomic and socio-demographic variables and the various DS. However, such issues have not been analysed specifically for older adults.

Other work within the 'bottom-up' approach has assumed that the subjective importance of a life domain moderates the effect of DS on LS, such that satisfactions with subjectively more important domains carry more weight in determining overall LS than satisfactions with subjectively less important domains. Hsieh (2003) provides evidence that considering the relative subjective importance weights of life domains improves the prediction of global LS from DS, compared to treating every life domain as having equal weight. This leads to the question whether the importance of certain life domains and the size of the effect of DS on LS might differ between older and younger adults. A likely 
hypothesis is that health and housing are more important in the very old, compared to the younger age groups—but this has yet to be tested.

\subsection{Theoretical status of SWB in causal networks}

The theoretical status of SWB in causal networks has been conceived differently in the literature, and these differences can be represented in four basic models (see Figure 1):

(1) Effect model. Most of the literature regards SWB as an effect: as the result of personal and/or environmental variables. Environmental factors can be described on different levels of analyses (micro, meso, macro, as described by Bronfenbrenner, 1979).

(2) Predictor model. A smaller part of the literature sees SWB as a cause of individual and social outcomes (such as health, longevity, voluntary engagements; see Lyubomirsky, King and Diener, 2005, for a review).

(3) Mediator model. Very few studies consider SWB as a mediating variable that is caused by personal and/or environmental factors-and which, in turn, has an effect on individual and/or social outcomes (see Murrell and Meeks, 2002).

(4) Moderator model. SWB could be regarded as a moderator (a third variable that may modify the effect of certain causes on certain outcomes). We did not find any study that analysed this role of SWB in older adults. 
(1)

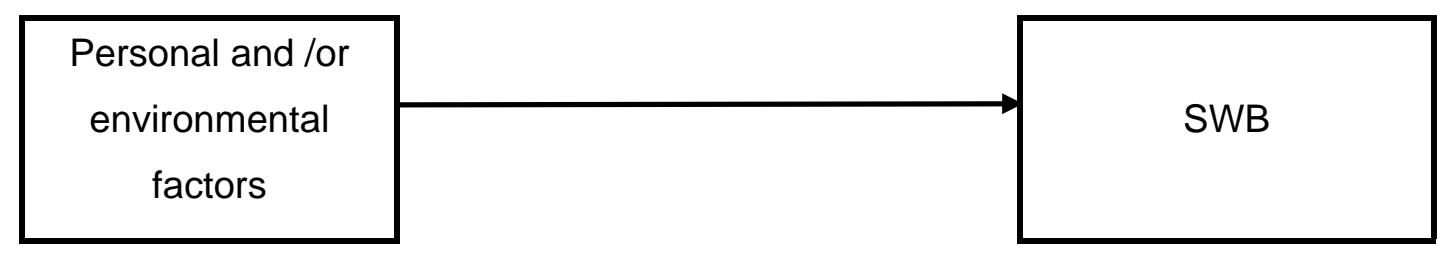

(2)

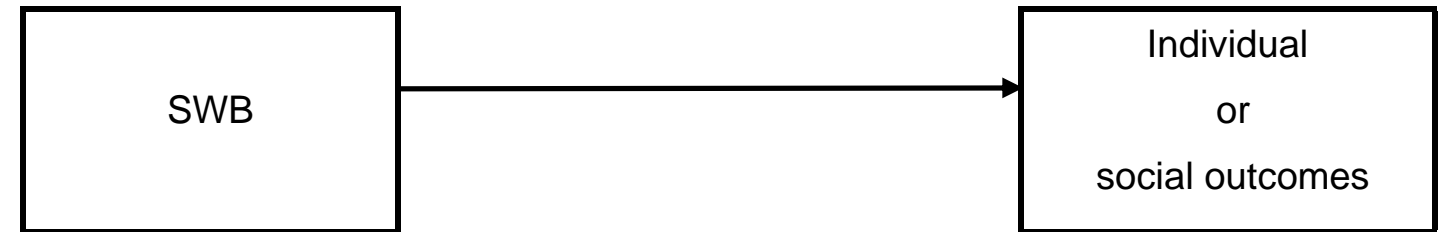

(3)

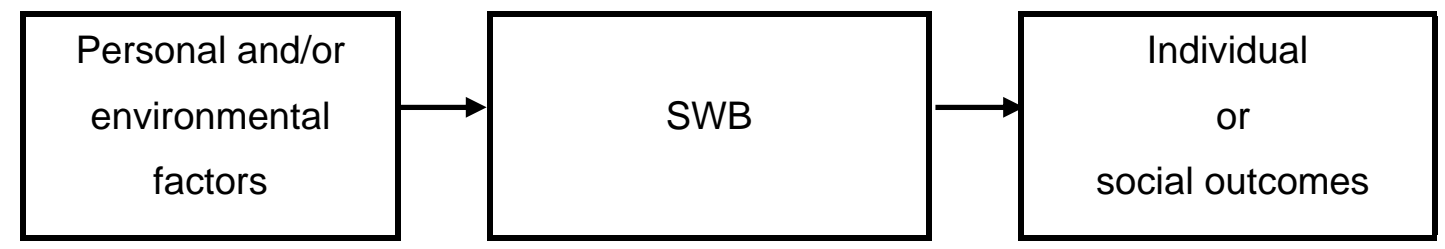

(4)

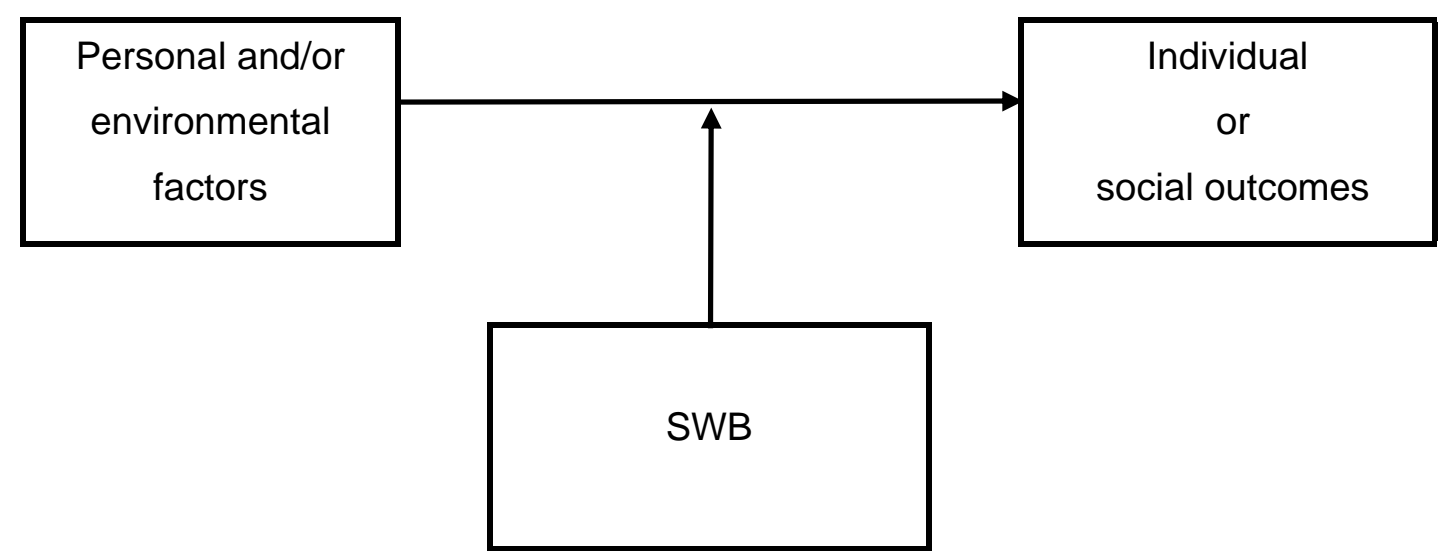

Figure 1: Theoretical status of SWB in causal networks.

The aforementioned models provide, however, a somewhat simplified linear picture of the causal relations. Effects of personal or environmental factors (such as critical life events) on SWB may also be moderated by other relevant variables (such as social support). Moreover (and as will become evident later), regulative models seem to be more appropriate for describing the theoretical status of the construct. These models realise an integrative view which incorporates all models depicted above: SWB is caused by personal and/or environmental factors; SWB has individual and/or social consequences; the level of SWB is perceived by the individual and evokes regulative responses on the part of him or her; regulative activities of the individual may lead to a change in SWB level (see section 2.5). 


\subsection{Main findings about developmental course, causes and consequences of SWB in older adults}

\subsubsection{SWB as a function of age}

To what extent does SWB level change with age? Competing hypotheses have been proposed.

- H1: A marked decrease of SWB occurs in old age. This hypothesis emerged from the common-sense assumption, and from gerontological evidence, that older persons face several losses (regarding health, autonomy, income, social relations...) that may interfere with their ability to get their needs met; frustration of needs, in turn, is assumed to decrease SWB.

- H2: Little or no change of SWB occurs in old age. This hypothesis was derived from research on personality factors in SWB: Because SWB is strongly related to personality traits (such as neuroticism or extraversion), which are very stable across adulthood (see DeNeve and Cooper, 1998; Diener et al., 2003; Lucas, 2008), little or no change in SWB should occur during that period of life. The little-or-no-change hypothesis can also be derived from three other lines of reasoning: From adaptationtheoretical considerations about SWB (Frederick and Loewenstein, 1999), from discrepancy-theoretical frameworks of satisfaction (see Thomae, 1970; Michalos, 1986), and action-theoretical models of regulation of SWB across the lifespan (see Baltes and Baltes, 1990; Brandtstädter and Rothermund, 2002).

Different empirical designs have been used to describe the actual developmental course of SWB in older adults. Numerous cross-sectional studies have compared groups of persons of different age at one point of measurement (for example, middle-aged- vs. old individuals). Narrative literature reviews (see Diener and Suh, 1998) and meta-analyses (see Pinquart, 1997, 2001) suggest that-despite losses-there is no pronounced decline in global life satisfaction. This phenomenon has been labelled as the 'paradox of subjective well being' (see Staudinger, 2000) or as the 'stability-despite-loss paradox of subjective well being' (see Schilling, 2006; Gerstorf, Ram, Röcke, Lindenberger et al., 2008).

However, cross-sectional studies cannot disentangle age effects from cohort effects (thus, whether the different SWB means found, for instance, between groups of 60-79versus 80-99 year-old individuals are due to differences in age or in birth cohort). In order to specifically detect age effects, several longitudinal studies have been performed; these studies measure SWB of the same individuals at two or more consecutive points of time. Most of them referred to the cognitive component of SWB (life satisfaction) as dependent variable (see Gerstorf, Ram, Röcke, Lindenberger et al., 2008; Gerstorf, Ram, Eastabrook, 
Schupp, et al., 2008; Mroczek and Spiro, 2005; Schilling, 2006), whereas only a few focused on the affective component of SWB (see Charles et al., 2001; Costa and McCrae, 1993; Kunzmann et al., 2000).

Regarding the cognitive component (life satisfaction), most longitudinal studies found a rather slight, sometimes even non-significant average decline in life satisfaction from middle- to old age (up to about 70 or 85 years). Studies that included also individuals beyond 85 years old up to $100+$ years found a more pronounced decline in very old age, compared to the earlier phases of old age (Gerstorf, Ram, Röcke, Lindenberger et al., 2008; Gerstorf, Ram, Eastabrook, Schupp, et al., 2008). Moreover, these studies also introduced a new perspective by analysing life satisfaction not merely as a function of chronological age (= distance from birth), but also as a function of 'distance from death', which is a variable presumably related to mortality processes. Distance from death explained more variance of change in life satisfaction than did chronological age (see also Palgi et al., 2010). Analyses with distance from death as independent variable also revealed two different stages of change in life satisfaction: A phase of slight decline occurring in a larger temporal distance from death ('preterminal decline') and a phase of a much steeper decline (thus, at least by factor 2) about four years before death ('terminal decline'). This decline was most pronounced in the oldest-old (85+) individuals. The decline of SWB in the very old may be even more pronounced than the empirical findings suggest: Dropout of subjects between successive points of measurement may lead to an underestimation of the real decrease of SWB, because older individuals with decreasing SWB can be expected to be less motivated and/or able to participate in the following measurement waves.

Notable inter-individual differences concerning the transition point between the two phases were found: Some people reached the terminal phase many years before they died, whereas others reached it just a few years before their death-and still others never entered this phase at all. However, these studies are still descriptive; the direction of causality remains open: Do mortality-related processes or do cognitions of impending death reduce life satisfaction? Or, does reduced life satisfaction promote mortality?

Two positions may be mentioned here: Authors of the working group around Paul Baltes have argued that 'psychological mortality', described by a decrease in SWB and reduced cognitive functioning, will precede physical mortality (Smith, 2002). On the other side is evidence from the Heidelberg centenarian study that there is-even in old agevariability in SWB, underlining the plasticity of SWB (Jopp and Rott, 2006).

With respect to the affective components of SWB, the longitudinal studies revealed a different developmental pattern of findings for positive vs. negative affect. In most studies, positive affect remained stable for the middle-aged to the young-old groups-but for the 
oldest-old groups, some decline of positive affect was documented (see Charles et al., 2001; Kunzmann et al., 2000). However, the evidence for age-related change in negative affect is mixed. Whereas some studies showed a notable decline of negative affect in the younger groups_albeit not in the oldest age groups (see Charles et al., 2001)—another study provided no longitudinal evidence for age-related change of negative affect (Kunzmann et al., 2000). Again, most longitudinal studies reported considerable inter-individual differences in the intra-individual change patterns (thus, positive affect of some older adults declined, whereas that of others increased or remained constant).

Isaacson and Smith (2003) show that a unique age effect on positive and negative affect diminishes if one controls for demographic-, personality-, health- and cognitivefunctioning variables. Using data from the Berlin Aging Study, the authors report that personality and general intelligence emerged as the strongest predictors of positive and negative affect. These findings reflect the fact that SWB is related to personality variables, but also to differing life conditions (thus, health, functional status). Health and functional problems may thus be more reliable predictors of positive and negative affect in old age, than in young or middle adulthood, where job and social relations constitute the main issues.

\subsubsection{SWB as a function of current life circumstances}

The following discussion relies on a meta-analysis of 286 empirical studies provided by Pinquart and Sörensen (2000). The authors analysed the association of socioeconomic status, social network and competence with SWB in old people; SWB was covered by life satisfaction, happiness and self-esteem measures. Four main findings may be summarised as follows.

First, the authors report significantly higher correlations of all three measures of SWB with income than with education (both being indicators of SES); this finding highlights the importance of the financial situation for SWB in old age. Second, competence (indicated by activities and instrumental activities of daily living) was related to SWB-the higher the competence, the higher the reported life satisfaction, happiness and self-esteem. Third, the quality of social contacts was more strongly related to all three SWB indicators than the quantity of social contacts. A specific finding was that the quantity of contact with friends was more important for all indicators of SWB in old age than quantity of contact with family and adult children. ${ }^{2}$ Fourth, age and gender moderated the relations between income and social contacts on the one hand and SWB indicators on the other.

\footnotetext{
${ }^{2}$ Kohli and Künemund (chapter 6 of this book) emphasise the importance of social networks for the well being of older adults. The authors speak of well being in general. Their propositions may thus
} 
Two gender effects were reported; first, the analysis showed that the relationship between SES and life satisfaction or happiness was stronger in the male samples; there was no significant influence of gender on the association between SES and self-esteem. Second, social contacts were more closely related to life satisfaction and happiness for women than for men; again, no effect emerged for self-esteem. Moderating effects of age were tested by contrasting a group with an age 70 years or less with a group above 70 years of age. Here, three effects were observed: (1) Life satisfaction and happiness showed a lower correlation with SES in the older group than in the younger group; (2) the correlation of SWB with social integration was larger for older participants than for younger participants; in the older samples, correlations between the quantity and the quality of social contacts with SWB were significantly higher than in younger samples; (3) a stronger relation between competence and happiness was reported for older compared with younger samples; no relations were found for life satisfaction and self-esteem.

All in all, the results highlight the possible importance of life circumstances for SWB in old adults: Low income, low educational status, low quality of social contacts, and functional deficits accompany reduced life satisfaction, low happiness and reduced self-esteem. However, the findings are only correlational ones; they do not allow for definitive causal inferences. More longitudinal and intervention studies are needed in order to justify such conclusions.

\subsubsection{SWB as a function of critical life events}

A few prospective longitudinal studies have been conducted with large and approximately representative samples in which SWB was assessed several years before and after the occurrence of age-related life events such as retirement, disability or widowhood, which thus provide additional data on the developmental course of SWB. The general result pattern here indicates that long-term levels of SWB do change in response to such events, and that the pattern of adaptation varies with the kinds of life events. Depending on the type of event, the adaptation of SWB (the return to the pre-event level) may be rather slow and may be incomplete. For instance, adaptation to widowhood took about seven years on average (see Lucas et al., 2003). SWB decline in response to severe disability turned out to be even more pronounced, and adaptation took either longer or never happened at all (Lucas, 2007a,b). Such studies also provide evidence for large individual differences in the amount of adaptation that may result from variation in concrete circumstances of the event type under

refer also to objective well being, and not exclusively to subjective well being, which is the primary focus of this chapter. 
consideration and/or from variability in the response of different persons to the same type of event.

Recent studies have also made preliminary attempts to analyse more deeply interindividual differences in event-related intra-individual change of SWB. In a latent-class analysis, Pinquart and Schindler (2007) found three groups of persons with different patterns of response to retirement (SWB decline followed by increase; initial increase but subsequent decrease; temporary small increase), and identified correlates of the different patterns of response. For instance, the group characterised by a decline in life satisfaction some time after retirement showed worse physical health, below-average age before retirement, unemployment before retirement, low socioeconomic state, and they lacked a spouse.

All in all, the notion holds that critical life events have an impact on SWB. As research indicates, the effect of critical life events is shaped by individual regulation. These processes have turned out to be a function of event characteristics (controllability, predictability, irreversibility), personal factors (habits, coping styles, competences) and context factors (such as social support); their specific interplay explains inter-individual and intra-individual differences in SWB across time (Filipp and Aymanns, 2010). It should be emphasised, as a specific point concerning the situation of the elderly person, that there is a heightened probability of critical life events (especially losses of persons and losses concerning physical and functional performance) with ongoing age. This qualifies especially old age as a period that sets heightened demands to individual regulation of SWB.

\subsubsection{SWB as a function of intentional activities}

Other potential determinants of SWB are intentional activities: those activities that people can choose to engage in and which require some degree of effort to enact. Whereas several empirical studies have examined their relation to SWB in samples of younger adults or in mixed-aged adult samples (for an overview, see Lyubomirsky, Sheldon, and Schkade, 2005), such studies specifically devoted to older adults are rare. A recent exception (Pushkar et al., 2010) investigated longitudinally how continuity and change of various intentional activities affected changes in positive and negative affect of retired men and women. Increased activity frequency as well as increased feelings of ability, ease and future intentions to perform such activities predicted higher positive affect; increases in felt ability and ease of activity predicted decreasing negative affect.

Links between a special subset of intentional activities (namely, socially-productive activities such as volunteering, informal helping, caring) and SWB have received special interest in research-but only a few studies have covered a broader range of such activities performed specifically by older adults. For instance, McMunn et al. (2009) examined links between various social activities (including paid work, voluntary work, caring for someone) 
and life satisfaction of participants of state-pension age or older. Participants in paid- or voluntary work showed more life satisfaction than non-participants, whereas carers and noncarers did not differ in life satisfaction. Such inconsistent findings suggest that one should differentiate carefully between the various kinds of such activities when analysing their relation to SWB. In contrast to the results of the aforementioned study, a meta-analysis of 84 studies comparing mainly older adult caregivers and non-caregivers found a significantly lower SWB among caregivers, and a substantial heterogeneity of effect sizes across studies (Pinquart and Sörensen, 2003). The extended literature on caregiving elucidates that caregiving is a rather heterogeneous category, which complicates the analysis of links to SWB. Caregiving by older adults may be addressed to different receivers (physically frail vs. demented spouses), may require various amounts of time and effort, may interfere differently with other goals of the caregiver, and may be associated with different amounts of strains and gains. Moreover, stress and coping models of caregiving (see for example Pinquart and Sörensen, 2005) suggest that the effect of caregiving on SWB may depend on the mix of the aforementioned factors and on the subjective interpretations of the caregiving situation-as well as on the availability of personal and social resources for coping with the given demands.

Voluntary work is another category of socially productive behaviour of older adults that has received the exclusive focus of some studies. In a meta-analysis based on 29 studies, Wheeler et al. (1998) found that older volunteers involved in direct (face-to-face) or indirect helping roles were characterised by a significantly greater quality of life (mostly indicated by measures of life satisfaction) compared to non-volunteers-even after controlling for health- and socioeconomic status of the participants. The effect was found to be more pronounced in studies involving direct (compared to indirect) helping relationships. More recent studies have found evidence for a positive relationship between the amount of volunteering and measures of SWB-either life satisfaction (van Willigen, 2000) or positive affect (Greenfield and Marks, 2004). However, the cross-sectional design of most studies precludes definitive causal inferences (thus, whether socially productive activities have an effect on SWB or vice versa, or whether some third variable-such as living conditions or personality traits-has an effect on both).

Siegrist and Wahrendorf (Chapter 5; this volume) review the literature and present data on links between socially productive activities (paid work, volunteering, informal helping) and well being as outcome variable. However, well being (WB) as conceived by these authors cannot be equated with subjective well being (SWB). Although both constructs have similar names and refer to the individual's point of view, their precise content differs substantially. Whereas SWB includes life satisfaction, domain satisfaction, and positive and negative affect as central elements (see section 2.1 of this chapter), WB is defined with 
reference to self-assessed health and to quality of life as indicated by the individual's sense of control, autonomy, self-realisation and pleasure. Thus, Siegrist and Wahrendorf provide valuable information about the effects of socially productive activities of (early) old adults in areas beyond SWB.

\subsubsection{Interventions to promote SWB in older adults}

Interventions to promote SWB in older adults may refer to different levels of the personenvironment relation. On the micro level, certain psycho-educational and psychotherapeutic approaches focus directly on the individual. Pinquart and Sörensen (2001) analysed 122 studies, and their findings in general support the assertion that psychosocial and psychotherapeutic interventions significantly reduce depression and improve psychosocial well being in older adults. The following factors were associated with improvement of life satisfaction and reduction of depression in older adults through specific interventions: (1) psychotherapeutic interventions (cognitive-behavioural therapy, relaxation, reminiscence) were more effective than psycho-educational ones (such as social activity programmes); additionally, cognitive-behavioural- as well control-enhancing strategies proved to be quite effective for nursing home residents; (2) interventions targeting already depressed persons before treatment were more effective than those addressing at-risk groups; (3) more than nine sessions produced better results than sessions with a lower number of contacts; (4) qualification of the therapist was a crucial factor in predicting reduction of depression and improvement of psychosocial well being. Moreover, nursing home patients reported greater reduction in depression, but not in life satisfaction compared to community resident older adults. Furthermore, the younger old (below the age of 77 ) showed a greater improvement in depression, but not in LS, compared to older persons (above the age of 77). All in all, one may conclude with Knight (2004) that the effectiveness of psychotherapy and mental health services in general has been established regarding older adults. Findings thus strongly support the development and elaboration of structures offering psychosocial intervention and psychotherapeutic interventions for these people.

Further approaches for promoting SWB of older adults are conceivable that refer to the meso- or macro level, such as local, regional or national policy measures. Social and transport policy initiatives are discussed as possible measures that could improve SWB by enhancing the provision of care (see Vaarama, 2009) or the out-of-home mobility for older adults (see Mollenkopf et al., 2004). To the best of our knowledge, their effectiveness has not yet been empirically evaluated.

Whereas empirical findings are still lacking, three different theoretical approaches already exist that allow for generating hypotheses concerning whether and how policy interventions may have an effect. These approaches, referring to the promotion of SWB in 
general, can easily be applied to the issue of enhancing SWB in older adults. First, mainstream economists (see Lewin, 1996) hold that SWB depends predominantly on one's objective living conditions (income, for example), and this leads one to expect that policy measures improving the objective living conditions of older adults will also increase their SWB. Second, some psychologists maintain that the effect of objective living conditions on SWB depends on internal processes. For instance, the 'hedonic treadmill model' assumes that individuals are characterised by set point levels of happiness, which in turn are determined by personality and genetic factors. A change of living conditions is expected to change a person's happiness above or below this set point, and adaptive processes are assumed to return the individual rather rapidly and completely to this point (see Brickman and Campbell, 1971). Viewed from this perspective, policy measures changing economic or social conditions could likely be regarded either as unnecessary or as having at least no permanent effects on SWB. However, this theoretical perspective (and the implied pessimism regarding interventions for improving well being) have been criticised in several respects, and revisions have been proposed to the 'hedonic treadmill model' that provide more hope for policymakers that sustainable change of SWB can be reached (Diener et al., 2006). Furthermore, cross-national research-especially findings comparing countries with differing socioeconomic and social welfare systems-makes it very likely that objective living conditions have an impact on SWB.

A third theoretical approach that has emerged among some economists and psychologists favours a moderate adaptation model: SWB is conceived as the outcome of both objective factors and subjective factors. For example, satisfaction with a certain life domain is assumed to result from the extent to which one's attainments in that life domain match one's aspirations (see Easterlin, 2006; Plagnol and Easterlin, 2008). Overall satisfaction, in turn, is conceived as the net outcome of the satisfaction with various life domains (including material life conditions, family life, health). This model can inspire two principle categories of policy measures for improving SWB in older adults. The first refers to measures for changing objective living conditions under the assumption that the aspirations regarding these conditions remain constant. The second one includes measures that aim at lowering the aspirations of older adults; this option is particularly relevant if objective living conditions cannot be changed. Obviously, much more needs to be known about the content, stability and modifiability of the aspirations of older adults' in order to anticipate the effectiveness of these two categories of policy measures for promoting SWB.

\subsubsection{Effects of SWB in older adults}

Based on prior analyses of adaptive effects of positive emotions, Lyubomirsky, King and Diener (2005) developed a conceptual model that proposes that positive affect (a central 
component of SWB) leads people to pursue positive goals and thus to be more 'successful' in various life domains. Moreover, these authors provide an extensive meta-analysis that tests their model against evidence from a total of 225 cross-sectional, longitudinal, and experimental studies on the link between positive affect and positive outcomes in the areas of social behaviour, social relationships, work performance, income, health, creativity and problem solving. They concluded that people who experience more positive affect are more likely to have good social relationships, higher incomes, superior work performance, more community involvement, and better health compared to people with less positive affect. Although the meta-analysis was not specifically devoted to older adults, about a dozen studies focussing on this age group were included in the meta-analysis, most of them referring to health-related outcomes of SWB: Positive affect turned out to be positively related to health or longevity, or to be negatively related to mortality. Future research should provide stronger evidence from intervention studies that SWB causes such outcomes. Moreover, the effects of positive affect and other components of SWB on positive outcomes beyond health should be investigated further.

\subsection{Theoretical models about SWB regulation in older adults}

The finding that despite age-linked losses there is no strong decline in at least some measures of SWB (such as life satisfaction) across age (with the exception of the terminal phases of life) has raised the question which regulative processes might account for that phenomenon. Several approaches have been proposed here, and the historically more important and/or scientifically more influential ones all stem from lifespan developmental psychology or psychological gerontology. One may list here Thomae's (1970) cognitive theory of ageing, the model of selective optimisation with compensation proposed by Baltes and Baltes (1990), the dual-process model of assimilative and accommodative coping by Brandstädter and colleagues (see Brandtstädter and Rothermund, 2002), as well as the motivational theory of lifespan development elaborated by Heckhausen et al. (2010). The primary focus of these models is on self-regulation of SWB through intentional or nonintentional processes of the individual. All of these theories claim that SWB in old age is open to regulation processes in which an objective life situation that may be 'good' or 'bad' is evaluated by the individual as either 'good' or 'bad'; a cross-classification of objective life situations and their subjective evaluation results in four constellations, depicted in Table 2.

Table 2: Cross-tabulation of objective life situations and their subjective evaluations.

\begin{tabular}{|l|l|l|}
\hline \hline Subjective evaluation & \multicolumn{2}{|c|}{ Objective life situation } \\
\cline { 2 - 3 } & Good & Bad \\
\hline
\end{tabular}




\begin{tabular}{|l|c|c|}
\hline \multirow{3}{*}{ Bad } & Well Being & Satisfaction paradox \\
\cline { 2 - 3 } & $\begin{array}{c}\text { Dilemma of } \\
\text { discontentment }\end{array}$ & Deprivation \\
\hline
\end{tabular}

Of particular interest are the two constellations in which subjective evaluation and objective life situation diverge (satisfaction paradox, dilemma of discontentment), pointing to the plasticity and the regulation of SWB (see Ferring and Filipp, 1997). When discussing the objective life situation in age, one should therefore keep in mind their transformation into subjective reality. Such a view should by no means foster a kind of 'pessimistic' view on the possible effects that an amelioration and elaboration of objective living conditions may have on SWB (see below).

\section{Remaining gaps in knowledge: Main challenges}

This section uses insights and arguments from the preceding sections to highlight knowledge gaps and indicate potential research directions on SWB in older adults. Theoretical, methodological and empirical issues will be covered.

\subsection{Measurement of SWB in older adults}

With respect to measurement of SWB, three points are deserving of further development.

\section{Sufficiently broad measurement of SWB}

SWB is an umbrella concept covering four constructs (namely, general life satisfaction, domain satisfaction, positive affect, and negative affect). In order to realise a comprehensive and sound measurement, not just one indicator of SWB should be used, but rather all four. To ensure psychometric quality, one should also use multiple indicators for each construct.

Measurement equivalence of self-report measures of SWB

Until now, little has been known about the extent to which frequently applied measures of SWB are equivalent for people of different age groups. Existing studies have been confined to comparisons between adolescents vs. older adults (Pons et al., 2000) or between youngold vs. oldest-old groups (Lawrence and Liang, 1988). Moreover, studies have considered just global measures of life satisfaction without taking into account measures of domain satisfaction. Given the importance of measurement equivalence for an adequate interpretation of comparisons of SWB means across age groups, more research is needed in this context. First, measurement equivalence should be examined across a broader range of age groups that cover all phases of adult life. Second, it should be clarified whether people of a different age rely on the same or on a different kind of information when they rate how 
satisfied they are with their life as a whole. People of a different age may rely on information about different domains of life when they rate global life satisfaction, given that the relative importance of health, financial situation and work decreases with age (Hsieh, 2005). Structural equation modelling is a powerful tool for testing the measurement equivalence of various domain satisfactions in relation to global life satisfaction as a latent variable.

$\underline{\text { Assessment of SWB in older adults with severe cognitive impairment: Beyond self-report }}$

More emphasis should be put on the further development of assessment approaches to SWB of older individuals with severe cognitive impairments who are unable to provide reliable and valid self-reports of their SWB. Even though SWB is by definition subjective, SWB can manifest itself not just in self-reports, but also in other verbal and nonverbal behaviour. ${ }^{3}$ Table 3 contains a classification of indicators of SWB on which future research may concentrate.

Table 3: Indicators of SWB beyond self-report

\begin{tabular}{|c|c|c|}
\hline \multirow[t]{2}{*}{ Component of SWB } & \multicolumn{2}{|c|}{ Indicator } \\
\hline & Verbal Behaviour & Non-verbal Behaviour \\
\hline Life satisfaction & $\begin{array}{l}\text { Scores aggregated across } \\
\text { domain-specific measures, as } \\
\text { described below }\end{array}$ & $\begin{array}{l}\text { Scores aggregated across } \\
\text { domain-specific measures, as } \\
\text { described below }\end{array}$ \\
\hline Domain satisfaction & $\begin{array}{l}\text { - } \quad \text { verbal reactions } \\
\text { - } \quad \text { para-verbal reactions } \\
\text { referring to real or symbolically } \\
\text { presented 'life domains' }\end{array}$ & $\begin{array}{l}\text { - } \quad \text { mimic and glance } \\
\text { - } \quad \text { gesture } \\
\text { - } \quad \text { posture } \\
\text { - } \quad \text { gross-bodily movement } \\
\text { referring to real or symbolically } \\
\text { presented 'life domains' }\end{array}$ \\
\hline Positive / negative affect & $\begin{array}{l}-\quad \text { verbal reactions } \\
-\quad \text { para-verbal reactions } \\
\text { referring to real or symbolically } \\
\text { presented 'life domains' }\end{array}$ & $\begin{array}{l}\text { - } \quad \text { mimic and glance } \\
\text { - } \quad \text { gesture } \\
\text { - } \quad \text { posture } \\
\text { - } \quad \text { gross-bodily movement } \\
\text { referring to real or symbolically } \\
\text { presented 'life domains' }\end{array}$ \\
\hline
\end{tabular}

To circumvent the cognitive limitations of the person in question in the assessment of such indicators, two kinds of informants can be referred to: (1) People having frequent

\footnotetext{
${ }^{3}$ However, if there is no evidence that an older person has at least a minimally differentiated mental representation of his or her life, the concept of 'life satisfaction' cannot be meaningfully used. Such an individual may still be 'satisfied' or 'dissatisfied' in an unspecified sense, but speaking of 'life satisfaction' would be misleading here.
} 
contact with the target person (family members, professional caregivers) and (2) People not related to the target person in daily life (independent observers). ${ }^{4}$

Future research will have to work out the details of the aforementioned behavioural indicators in guidelines and instruments for their assessment. Because the presence of positive and absence of negative affect are important components of SWB, it should be fruitful to use theoretical and methodological knowledge from research on affects (see Coan and Allen, 2007) in projects developing SWB measures for older adults with severe cognitive impairments. Some of these studies should also provide a further analysis of biases that external observers (such as family members or professional caregivers) manifest in rating SWB of older persons.

\subsection{Limited age range and age segmentation in studies on SWB in older adults}

The upper end of the age scale has been rather low in many gerontological studies; in particular, there is a scarcity of very old people (85+) in most studies, which may be explained by their comparatively poor functional state. Moreover, the oldest age group is defined rather broadly and differently in many studies (50+, 65+ and so forth). It is thus impossible to get specific information of SWB in more narrowly defined age groups (80-85, $85-90, \ldots)$ and to describe the development of SWB within the category of older adults aged $65+$. A few studies offer a more differentiated / fine-grained scaling of the age variable up to $100+$ years, which points in the right direction; we need more studies of that kind in future.

\subsection{Lack of representative and longitudinal studies on SWB in older adults}

There are just a few European studies on SWB in older adults based on sufficiently representative samples. Only some of these studies have a longitudinal design (see also below): The German Socio-Economic Panel, the German Aging Survey ${ }^{5}$, the British Household Panel Study, the Eurobarometer, and the Survey on Health, Ageing and

\footnotetext{
${ }^{4}$ Past research has also relied on these kinds of informants to get information about objective/external life circumstances or about the competences of elderly individuals.

${ }^{5}$ German Ageing Survey: Nationwide representative cross-sectional and longitudinal survey of the German population aged over 40. Up to now, the survey has had three waves of assessment (1996, $2002,2008)$ that cover material living conditions, critical life events, health, social relationships, activities, self-concept and life goals, quality of life and SWB.
} 
Retirement. All of these studies cover extended periods of time and include several points of measurement.

However, studies can be representative only to a certain degree. Because in democracies participation in empirical studies is voluntary, self-selection may occur. This problem is more serious in gerontological studies. Overestimations of SWB may result already in cross-sectional studies, if the self-selection of older participants is correlated with the level of SWB, such that individuals with higher SWB are more likely to participate, whereas individuals with lower SWB will more likely refuse participation. A biased estimation of the developmental course of SWB is likely to occur in longitudinal studies, too, if the dropout in the following waves of measurement is correlated with the change (the decline) of SWB. The actual decrease of SWB in very old age may be underestimated if individuals with decreasing SWB become less motivated or able to participate in subsequent measurement waves. Moreover, given that $13 \%$ of older adults between $80-85$, and $21 \%$ of older adults between 85 and 90 are (severely) demented in Europe ${ }^{6}$ (and thus may be unable and/or not sufficiently motivated to participate in a normal survey), the dropout rate is considerable, and results may be rather biased. So, a check of representativeness and a dropout analysis should be integrated in these studies, and findings should be interpreted in light of systematic selection biases.

\subsection{Ignorance about the causes of SWB in older adults}

SWB is not the product of a monocausal process; it is caused and initiated by several interlinked factors on the societal and individual level. With respect to its causal links, equifinality (that is, differing causes and conditions leading to similar results) and multifinality (that is, similar causes and conditions leading to differing results) may be considered, and causes have to be analysed in their linear as well as non-linear interrelation.

The exploration of causal relations requires more appropriate research designs (such as prospective longitudinal studies, experimental/intervention studies and adequate causal modelling data analyses) - and here, there is also a considerable research gap; studies should also examine effects not just of inter-individual variation, but also of intraindividual change in external life circumstances on SWB (see Lucas et al., 2003, 2007a,b); studies should also look for differential trajectories of life circumstances (see Pinquart and Schindler, 2007, for an innovative approach).

\footnotetext{
${ }^{6}$ European Community Concerted Action on the Epidemiology and Prevention of Dementia group (2009). Retrieved at: http://www.dementia-in-europe.eu/?Im2=HIXPJGBKGFTQ
} 


\subsection{Lack of knowledge about the regulation of SWB in older adults}

Existing models of SWB regulation focus predominantly on processes related to the individual him- or herself (see section 2.5). However, the regulation of older adults' SWB could also involve their interaction partners. To distinguish this phenomenon from an individual's self-regulation, we call it cooperative regulation of SWB: this kind of regulation has been widely neglected in previous research. The following processes seem to be involved in the cooperative regulation of SWB in a dyad consisting of $A$ (the older person) and $B$ (a family member, a friend, a neighbour, a co-resident in a nursing home or a professional caregiver):

(1) A communicates his or her SWB to B,

(2) B perceives, interprets and evaluates this message,

(3) B acts toward A with the intention to influence (increase) A's SWB.

Researchers may import concepts and methods from other relevant fields of inquiry, such as communication of emotions, self-disclosure, perception and recognition of emotion, emotional intelligence and mobilisation of support. Moving from dyads to larger social system research should also focus on (a) how information about SWB level of a group of individuals is conveyed (through expert hearings or through the media, for example) to responsible agents in care institutions or in political systems and (b) how this information is used (if at all) in the planning and implementation of policy measures to raise SWB. The notion of 'cooperative regulation' will certainly allow better representation of the complexity of SWB regulation by older adults in their social context. This will also challenge methodology, because dyadic or 'polyadic' assessment strategies will have to be further developed.

\subsection{Lack of knowledge about consequences of SWB in older adults}

Although there is growing research within 'positive psychology' focussing on SWB as a resource for optimal functioning of individuals (see Gable and Haidt, 2005), few studies adequately explore the (positive) effects that SWB of older adults may have on individual and social outcomes.

\subsection{Lack of knowledge about effective policy measures to promote SWB in older adults}

As already mentioned in subsection 2.4.5, empirical studies of the outcomes of policy measures for promoting SWB in older adults are still missing. This subsection considers the major determinants of SWB that might be influenced by policy interventions: Living 
conditions, critical life events and intentional activities. In considering these factors, one must, of course, bear in mind that for some of them further research is already needed to establish their causal relevance. The subsequent arguments are under the proviso that such evidence can be provided.

Living conditions. Global life satisfaction is systematically related to domain satisfaction regarding one's family life, financial situation, health condition, and job situation (the latter will be relevant only for older adults still working). Policy measures aiming to improve SWB should focus on the living conditions that are likely to contribute to the domain satisfaction in question. Relevant policy measures will thus refer to an improvement of the financial situation (such as public transfers to the poor aged, guaranteed minimum pensions), of health (such as community health and care services, prevention and curing programs, health and dependency insurances) and of family life or social contact more generally (such as programs for facilitation of out-of-home mobility).

Age-related life events. Although severe illness, functional disability and widowhood all have pronounced effects on SWB, substantial inter-individual differences in response to these events have been documented. Policy measures may help to prevent or postpone these life events (such as disease prevention, health education) and may facilitate coping with them if they occur (through promotion of healthcare, rehabilitation measures, psychotherapeutic counselling).

Intentional activities. Policy measures can help to expand the amount, range, quality and flexibility of opportunities for intentional activities, in general, and for socially productive activities, in particular. They may encourage older adults in performing them not just for the sake of their own SWB, but also for the benefit of communities.

\section{Current state of play of European research infrastructures and networks}

This section outlines the existing longitudinal studies and existing research infrastructures in Europe. In so doing, we make no claim to be comprehensive, given that several new programmes may already be under consideration by the European Commission.

Longitudinal studies. The following table lists ongoing or already finished longitudinal studies in Europe based on information provided by the US NIH National Institute on Aging. Already at the level of this crude tabulation is it evident that existing studies differ in age-group composition of their samples and in the covered time spans. Furthermore, only the Survey on Health, Aging and Retirement (SHARE) is a 'truly' European study-although not all European countries are involved (11 countries were included in the first wave, 16 in the third wave). 
Table 4: Longitudinal studies on ageing in Europe

\begin{tabular}{|l|l|l|l|}
\hline \hline Acronym & Title & $\begin{array}{l}\text { Age groups/ } \\
\text { Age range }\end{array}$ & Start/end \\
\hline BOLSA & Bonn Longitudinal Study of Aging & $60-75$ & $1965-1984$ \\
\hline BASE & Berlin Aging Study & $70-105$ & $1990-2000$ \\
\hline ELSA & English Longitudinal Study of Aging & $50+$ & $2002-$ \\
\hline Excelsa & Cross-European Longitudinal Study of Ageing & $30-85$ & $2002-$ \\
\hline H70 & Gothenburg Study (Göteborg) & 70 & $1971-2001$ \\
\hline ILSE & $\begin{array}{l}\text { Interdisciplinary Longitudinal Study of Adult } \\
\text { Development }\end{array}$ & $41-43,61-63$ & $1994-1998$ \\
\hline ILSA & Italian Longitudinal Study on Aging & $65-84$ & $1992-2004$ \\
\hline LASA & Longitudinal Aging Study Amsterdam & $55-85$ & $1992-2002$ \\
\hline Lund 80+ & Lund 80+ & 80 & 1988 \\
\hline MAAS & Maastricht Aging Study & $24-81$ & 1992 \\
\hline NLSAA & $\begin{array}{l}\text { Nottingham Longitudinal Study of Activity and } \\
\text { Ageing }\end{array}$ & $65+$ & $1983-193$ \\
\hline Rotterdam & Rotterdam Study & $55+$ & $1990-1999$ \\
\hline SAP & Southampton Ageing Project & $65+$ & $1977 / 78-$ \\
\hline SHARE & $\begin{array}{l}\text { Survey on Health, Ageing, and Retirement in } \\
\text { Europe }\end{array}$ & $50+$ & 1998 \\
\hline TamELSA & Tampere Longitudinal Study on Aging & $60-89$ & $1979-1999$ \\
\hline \hline
\end{tabular}

Source: National Institute on Aging, NIH

(http://www.nia.nih.gov/ResearchInformation/ScientificResources).

Although the list may at first glance seem impressive, a second look shows that obtaining sound information about the ageing process, in general, and regulating SWB in old people, in particular, requires further longitudinal research as a collaborative European effort. Research infrastructures and networks related to SWB in older adults. Several research networks and studies have been implemented (especially starting with the Fifth Framework Programme); in addition, regular representative surveys of the general and the older population have been initiated, in the meantime. Networks, work groups and surveys are listed in the following table. Again, we do not claim to be exhaustive here.

Table 5: European research infrastructures, networks, and surveys related to SWB in older adults 
- ENABLE-AGE: Enabling Autonomy, Participation and Well-Being in Old Age: The Home Environment as a Determinant for Healthy Aging (2002-2004).

http://www.enableage.arb.lu.se/index.html

- ESAW: European Study on Adult Well-Being (2002-2003). http://esaw.bangor.ac.uk//

- OASIS: Old Age and Autonomy: The Role of Service Systems and Intergenerational Family Solidarity; non-European participant: Israel (2000-2004). http://oasis.haifa.ac.il/

- EUROFAMCARE: Family care for older people in Europe (2003-2005). http://www.uke.de/extern/eurofamcare/

- MOBILATE: Enhancing outdoor activities in later life. Personal Cooping, environmental resources and technical support (2000-2002). http://www.istworld.org/ProjectDetails.aspx?Projectld=a5707e88509e4a5abe798cc27b86e268

- $\quad$ ERA-AGE - European Research Area in Ageing (2004-2009). http://era-age.group.shef.ac.uk/

- $\quad$ ERA-AGE2 European Research Area in Ageing (2009-) http://era-age.group.shef.ac.uk/

- FLARE Future Leaders in Aging Research (2007-). http://era-age.group.shef.ac.uk/content/188/

- FUTURAGE: A Road Map for Aging Research (2009-). http://futurage.group.shef.ac.uk/

\section{Regular representative surveys: General and older adult population}

- Eurobarometer (twice a year). http://ec.europa.eu/public_opinion/index_en.htm

- $\quad$ EVS: European Values Study (1981, 1990, 1999, 2008). http://www.europeanvaluesstudy.eu/

- ECHP: European Community Household Panel (1994-2001: every year). http://epp.eurostat.ec.europa.eu/portal/page/portal/microdata/echp

- ESS: European Social Survey (twice a year). http://ess.nsd.uib.no/ 


\section{Required research infrastructures, methodological innovations, data, networks and so forth- and consequences for research policy}

This section highlights some potential directions of SWB research, beginning with a focus on SWB measurement. First, additional research programmes are needed that coordinate existing research and synthesise existing evidence in order to refine measures of SWB in older adults. Subsequently, a research programme is needed that develops and adapts measures of SWB for older adults with advanced neurodegenerative diseases, since these individuals are unable to fill out questionnaires, let alone handle experience samplers.

A further avenue for research has to do with the implementation of a research infrastructure for a 'SWB Monitor in Older Adults'. Such a monitor should include an ongoing measurement of SWB in representative samples using multiple indicators of different type and specificity, assessed at several times of measurement. This would best be realised by a prospective longitudinal study of long duration. Existing studies-such as the German SocioEconomic Panel or the British Household Panel Study-could be refined in such a direction by including more-elaborate SWB measures as well as measures of additional causes and outcomes of SWB in old age. Besides (and complementary to) this, a cooperative transdisciplinary network should be established. This network should include SWB researchers of the general population, gerontologists, economists, and representatives from other relevant disciplinary groups (such as medical doctors, sociologists).

\section{What (and when) can we deliver on policy questions?}

SWB in older adults constitutes a large research domain that has already produced an impressive body of knowledge. Only the major essentials will be summarised here and combined with reflections about their significance for policy questions in this field. As a general point we would like to emphasise that strategies for communicating research findings to policymakers have to be further elaborated in the future so that these may have a greater impact on political decision-making.

\section{(1) Knowledge about the concept of SWB and its assessment}

Researchers of SWB in older adults have broadly agreed upon a definition of SWB that emphasises the individual's point of view in evaluating his or her life. This reflects a distinct component of older adults' quality of life beyond objective dimensions that deserves more attention by policymakers. The internal structure of SWB has been clarified (such as cognitive and affective components; general and domain-specific facets and their interrelation), and several instruments for assessing the various components of SWB of older 
adults are available. The reliability of the instruments has been established-and also some necessary conditions for their validity. Future research may provide further refinement-for instance, with respect to measurement devices for older adults with cognitive impairments.

\section{(2) Descriptive knowledge}

Longitudinal studies have revealed the course of SWB in later life. A rather small decline from middle- to old age and a pronounced decline in very old age have been found (especially large in the final years before death). However, notable inter-individual deviations from this average course have been documented. Further research is needed in order to deliver more differentiated information about the amount and kind of inter-individual differences and intra-individual change in SWB.

\section{(3) Knowledge about effects}

Although one cannot assume a direct causal relationship, the present evidence indicates that SWB may promote health and longevity in older adults. Future research may find additional positive outcomes beyond health that have already been documented for younger age groups: Positive social relationships, socially productive behaviour and creativity. Thus, SWB of older adults isn't just relevant because it reflects a pleasant experience, but also because it has positive individual and social consequences which then reinforce a positive SWB.

\section{(4) Knowledge about potential causes}

Important potential causes of SWB in older adults have been identified in the area of current life circumstances (regarding financial situation, social relationships). Future research should provide stronger evidence for their causal role through longitudinal and intervention studies. Age-related losses (such as death of spouse, or becoming severely disabled) have also been described as potential causes of SWB changes. Prospective longitudinal studies have shown here a large decline of SWB after the event, which shows a rather slow return (and sometimes even no return) to the pre-event level over the years.

Various kinds of intentional activities (such as socially productive behaviour) have also been identified as systematically related to SWB in older adults. The amount, type and particular circumstances appear to moderate the relation between these activities and SWB.

Theoretical models of SWB in older adults can provide a deeper explanation of welldocumented phenomena regarding SWB (for example, having to do with the stability-despiteloss-paradox; and individual and temporal differences in response to similar circumstances). The best available models are cognitively oriented and assume that not reality per se (such as living conditions, critical life events) determines SWB, but rather reality as subjectively perceived and evaluated by the individual in relation to his or her desires (needs, aspirations, goals and so forth). Fulfilment of desires is assumed to promote, and frustration of desires is 
assumed to deteriorate, SWB. Given the central role of reality perceptions and desires for SWB, more knowledge is needed about the content and the dynamic of these mental states of older adults.

\section{(5) Knowledge relevant for interventions}

Effective psychotherapeutic interventions for improving SWB in older adults are available; such interventions operate on a micro level and focus directly on the individual. Interventions operating on the meso- or macro level (and which may be instantiated by policy measures) can be further developed in future. Theoretical frameworks (for example, models about SWB and its regulation) and some robust empirical findings are already available; these frameworks can guide the construction and implementation of such interventions. This knowledge will also help in getting a realistic view of the chances and limits of policy measures to influence SWB. According to well-founded models of SWB, the effects of policy measures (intended, for example, to improve financial, social and health conditions) ultimately depend not primarily on changed living conditions per se, but rather on how they are perceived and evaluated by older adults in relation to their desires. Thus, any planning, implementation and evaluation of policy measures should pay attention to how living conditions are actually appraised. Based on such studies, public communication strategies can be used to influence SWB by changing older adult's perceptions and desires.

\section{A short outlook}

In closing, we would like to emphasise that in a European society in which the proportion of older persons is continuously increasing, while the proportion of children, adolescents and younger adults is continuously decreasing, research on conditions that guarantee and enhance SWB in old age (and other age groups) will become increasingly important. This research is and will be multidisciplinary, as is reflected by the various disciplines that are already engaged here. Still needed is better coordination of these disciplinary and complementary approaches; last but not least, this may also improve the impact of specific research findings on social policy measures for older adults. 


\section{References}

Andrews, F.M. and S.B. Withey (1976) Social Indictors of Well-being (New York: Plenum Press).

Baltes, P.B. and M.M. Baltes (1990) 'Psychological Perspectives on Successful Aging: The Model of Selective Optimization with Compensation' in P.B. Baltes and M.M. Baltes (eds) Successful Aging: Perspectives from the Behavioral Sciences (New York: Cambridge University Press), pp. 1-34.

Bradburn, N.M. (1969) The Structure of Psychological Well-being (Chicago: Aldine).

Brandtstädter, J. and K. Rothermund (2002) 'The Life-course Dynamics of Goal Pursuit and Goal Adjustment: A Two-process Framework'. Developmental Review, 22, 117-150.

Brickman, P. and D.T. Campbell (1971) 'Hedonic Relativism and Planning the Good Society' in M.H. Appley (ed.) Adaptation Level Theory: A Symposium (New York: Academic Press), pp. 287-302.

Bronfenbrenner, U. (1979) The Ecology of Human Development: Experiments by Nature and Design (Cambridge: Harvard University Press).

Charles, S.T., C.A. Reynolds and M. Gatz (2001) 'Age-related Differences and Change in Positive and Negative Affect over 23 Years'. Journal of Personality Assessment, 80, 136-151.

Coan, J.A. and J.J.B. Allen (eds) (2007) Handbook of Emotion Elicitation and Assessment (New York: Oxford University Press).

Costa, P.T. and R.P. McCrae (1993) 'Psychological Research in the Baltimore Longitudinal Study of Aging'. Zeitschrift für Gerontologie, 26, 138-141.

Cummins, R.A., R. Eckersley, J. Pallant, J. van Vugt and R. Misajon (2003) 'Developing a National Index of Subjective Wellbeing: The Australian Unity Wellbeing Index'. Social Indicators Research, 64, 159-190.

DeNeve, K.M. and H. Cooper (1998) 'The Happy Personality: A Meta-analysis of 137 Personality Traits and Subjective Well-being'. Psychological Bulletin, 124, 197-229.

Diener, E. (2006) 'Guidelines for National Indicators of Subjective Well-being and III-being'. Applied Research in Quality of Life, 1, 151-157.

Diener, E. and M.E. Suh (1998) 'Subjective Well-being and Age: An International Analysis', Annual Review of Gerontology and Geriatrics, 17, 304-324. 
Diener, E., P. Kesebir and R. Lucas (2008) 'Benefit of Accounts of Well-being - for Societies and for Psychological Science', Applied Psychology: An International Review, 57, 3753.

Diener, E., R.E. Lucas and C. Scollon (2006) 'Beyond the Hedonic Treadmill: Revising the Adaptation Theory of Well-being', American Psychologist, 61, 305-314.

Diener, E., S. Oishi and R.E. Lucas (2003) 'Personality, Culture, and Subjective Well-being: Emotional and Cognitive Evaluations of Life', Annual Review of Psychology, 54, 403425.

Diener, E., R.A. Emmons, R.J. Larsen and S. Griffin (1985) 'The Satisfaction with Life Scale', Journal of Personality Assessment, 49, 71-75.

Easterlin, R.A. (2006) 'Life Circle Happiness and its Sources: Intersections of Psychology, Economics and Demography', Journal of Economic Psychology, 27, 463-482.

Easterlin, R.A. and O. Sawangfa (2007) 'Happiness and Domain Satisfaction: Theory and Evidence', Bonn: IZA discussion paper 2584.

Ferri, C.P., M. Prince, C. Brayne, H. Brodaty, L. Fratiglioni, M. Ganguli, K. Hall, K. Hasegawa, H. Hendrie, Y. Huang, A. Jorm, C. Mathers, P. R Menezes, E. Rimmer, M. Scazufca, for Alzheimer's Disease International (2005) 'Global Prevalence of Dementia: A Delphi Consensus Study', Lancet, 366, 2112-2117.

Ferring, D. and S.-H. Filipp (1997) 'Subjektives Wohlbefinden im Alter: Struktur- und Stabilitätsanalysen' [Subjective Well-being in Old Age: Analyses of Structure and Stability], Psychologische Beiträge, 39, 236-258.

Ferring, D., C. Balducci, V. Burholt, C.G. Wenger, F. Thissen, G. Weber and I. HallbergRahm (2004) 'Life Satisfaction of Older People in Six European Countries: Findings from the European Study on Adult Well-being', European Journal of Ageing, 1, 15-25.

Filipp, S.-H. and P. Aymanns (2010) Kritische Lebensereignisse und Lebenskrisen [Critical Life Events and Life Crises] (Stuttgart: Kohlhammer).

Frederick, S. and G. Loewenstein (1999) 'Hedonic Adaptation' in D. Kahneman, E. Diener and N. Schwarz (eds) Well-being: The Foundations of Hedonic Psychology (New York: Sage), pp. 302-329.

Gable, S.L. and J. Haidt (2005) 'What (and Why) is Positive Psychology?' Review of General Psychology, 9, 103-110.

Gerstorf, D., N. Ram, C. Röcke, U. Lindenberger and J. Smith (2008) 'Decline in Lifesatisfaction in Old Age: Longitudinal Evidence for Links to Distance to Death, Psychology and Aging, 23, 154-168. 
Gerstorf, D., N. Ram, R. Estabrook, J. Schupp, G.G. Wagner and U. Lindenberger (2008) 'Life Satisfaction Shows Terminal Decline in Old Age: Longitudinal Evidence from the German Socio-Economic Panel Study (SOEP)', Developmental Psychology, 44, 1148-1159.

Greenfield, E.A. and N.F. Marks (2004) 'Formal Volunteering as a Protective Factor for Older Adults' Psychological Well-being', Journals of Gerontology: Series B: Psychological Sciences and Social Sciences, 59B, S258-S264.

Heckhausen, J., C. Wrosch and R. Schulz (2010) 'A Motivational Theory of Life-span Development', Psychological Review, 117, 32-60.

Hsieh, C.-M. (2003) 'Counting Importance: The Case of Life Satisfaction and Relative Domain Importance', Social Indicators Research, 61, 227-240.

Hsieh, C.-M. (2005) 'Age and Relative Importance of Major Life Domains', Journal of Aging Studies, 19, 503-512.

Isaacson, D. and J. Smith (2003) 'Positive and Negative Affect in Very Old Age', Journals of Gerontology Series B: Psychological Sciences and Social Sciences, 58, P143-P152.

Jopp, D. and C. Rott (2006) 'Adaptation in Very Old Age: Exploring the Role of Resources, Beliefs, and Attitudes for Centenarians' Happiness', Psychology and Aging, 21, 266280.

Kahneman, D., A.B. Krueger, D.A. Schkade, N. Schwarz and A.A. Stone (2004) 'A Survey Method for Characterizing Daily Life Experience: The Day Reconstruction Method', Science, 306, 1776-1780.

Knight, B. (2004) Psychotherapy with Older Adults (New York: Sage).

Kohli, M. and H. Künemund (2010) 'Social Networks' in L. Bovenberg, A. van Soest and A. Zaid (eds) Aging, Health and Pensions in Europe (Houndmills, Basingstoke, Hampshire: Palgrave Macmillan), pp. xxx-yyy.

Kunzmann, U., T.D. Little and J. Smith (2000) 'Is Age-related Stability of Subjective Wellbeing a Paradox? Cross-sectional and Longitudinal Evidence from the Berlin Aging Study', Psychology and Aging, 15, 511-526.

Lawrence, R.H. and J. Liang (1988) 'Structural Integration of the Affect Balance Scale and the Life Satisfaction Index A: Race, Sex and Age Differences', Psychology and Aging, 3, 375-384.

Lewin, S. (1996) 'Economics and Psychology: Lessons for our Own Day from the Early Twentieth Century', Journal of Economic Literature, 34, 1293-1323. 
Logsdon, R.G., L.E. Gibbons, S.M. McCurry and L. Teri (2002) 'Assessing Quality of Life in Older Adults with Cognitive Impairment', Psychosomatic Medicine, 64, 510-519.

Lucas, R.E. (2007a) 'Adaptation and the Set-point Model of Subjective Well-being. Does Happiness Change after Major Life Events?', Current Directions in Psychological Science, 16, 75-79.

Lucas, R.E. (2007b) 'Long-term Disability is Associated with Lasting Changes in Subjective Well-being: Evidence from Two Nationally Representative Longitudinal Studies', Journal of Personality and Social Psychology, 92, 717-730.

Lucas, R.E. (2008) 'Personality and Subjective Well-being' in M. Eid and R.J. Larson (eds), The Science of Subjective Well-being (New York: Guilford Press), pp. 171-194.

Lucas, R.E., A.E. Clark, Y. Georgellis and E. Diener (2003) 'Reexamining Adaptation and the Set Point Model of Happiness: Reactions to Changes in Marital Status', Journal of Personality and Social Psychology, 84, 527-539.

Lyubomirsky, S., L. King and E. Diener (2005) 'The Benefits of Frequent Positive Affect: Does Happiness Lead to Success?' Psychological Bulletin, 131, 803-855.

Lyubomirsky, S., K.M. Sheldon and D. Schkade (2005) 'Pursuing Happiness: The Architecture of Sustainable Change', Review of General Psychology, 9, 111-131.

McMunn, A., J. Nazroo, M. Wahrendorf, E. Breeze and P. Zaninotto (2009) 'Participation in Socially-productive Activities, Reciprocity and Wellbeing in Later Life: Baseline Results in England', Ageing and Society, 29, 765-782.

Michalos, A.C. (1986) 'An Application of Multiple Discrepancies Theory (MDT) to Seniors', Social Indicators Research, 18, 349-373.

Mollenkopf, H., F. Marcellini, I. Ruoppila, Z. Széman, M. Tacken and H.-W. Wahl (2004) 'Social and Behavioural Science Perspectives on Out-of-home Mobility in Later Life: Findings from the European Project MOBILATE', European Journal of Ageing, 1, 4553.

Mroczek, D.K. and A. Spiro III (2005) 'Change in Life Satisfaction During Adulthood: Findings from the Veterans Affairs Normative Aging Study', Journal of Personality and Social Psychology, 88, 189-202.

Murrell, S.A. and S. Meeks (2002) 'Psychological, Economic and Social Mediators of the Education-health Relationship in Older Adults', Journal of Aging and Health, 14, 527550.

Palgi, Y., A. Shrira, M. Ben-Ezra, T. Spalter, D. Shmotkin and G. Kave (2010) 'Delineating Terminal Change in Subjective Well-being and Subjective Health: Brief Report', 
Journals of Gerontology Series B: Psychological Sciences and Social Sciences, 65B, 61-64

Pinquart, M. (1997) 'Selbstkonzept- und Befindensunterschiede im Erwachsenenalter: Ergebnisse von Metaanalysen', [Differences in Self-concept and Well-being across the Adult Life Span: Results of Meta-analyses]. Zeitschrift für Gerontopsychologie und -Psychiatrie, 10, 17-25.

Pinquart, M. (2001) 'Age Differences in Perceived Positive Affect, Negative Affect and Affect Balance in Middle and Old Age', Journal of Happiness Studies, 2, 375-405.

Pinquart, M. and I. Schindler (2007) 'Changes of Life Satisfaction in the Transition to Retirement: A Latent-class Approach', Psychology and Aging, 22, 442-455.

Pinquart, M. and S. Sörensen (2000) 'Influences of Socioeconomic Status, Social Network, and Competence on Subjective Well-being in Later Life: A Meta-analysis', Psychology and Aging, 15, 187-224.

Pinquart, M. and S. Sörensen (2001) 'How Effective are Psychotherapeutic and Other Psychosocial Interventions with Older Adults? A Meta-analysis', Journal of Mental Health and Aging, 7, 207-243.

Pinquart, M. and S. Sörensen (2003) 'Differences Between Caregivers and Noncaregivers in Psychological Health and Physical Health: A Meta-analysis', Psychology and Aging, $18,250-267$.

Pinquart, M. and S. Sörensen (2005) 'Caregiving Distress and Psychological Health of Caregivers' in K.V. Oxington (ed.) Psychology of Stress (New York: Nova Science Publishers), pp. 165-206.

Plagnol, A.C. and R.A. Easterlin (2008) 'Aspirations, Attainments and Satisfaction: Life Cycle Differences between American Women and Men', Journal of Happiness Studies, 9, 601-619.

Pons, D., F.L. Atienza, I. Balaguer and M.L. Garcia-Merita (2000) 'Satisfaction with Life Scale: Analysis of Factorial Invariance for Adolescents and Elderly Persons', Perceptual and Motor Skills, 91, 62-68.

Pushkar, D., J. Chaikelson, M. Conway, J. Etezadi, C. Giannopoulus, K. Li and C. Wrosch (2010) 'Testing Continuity and Activity Variables as Predictors of Positive and Negative Affect in Retirement', Journals of Gerontology Series B: Psychological Sciences and Social Sciences, 65B, 42-49.

Roick, C., A. Hinz and H.-J. Gertz (2007) 'Kann Lebensqualität bei Demenzkranken Valide Bestimmt Werden? Eine Aktuelle Übersicht über Messinstrumente und Methodische 
Probleme' [Is Quality of Life in Dementia Patients Validly Estimable? A Current Review about Measuring Instruments and Methodological Problems], Psychiatrische Praxis, 34, 108-116.

Schilling, O. (2006) 'Development of Life Satisfaction in Old Age: Another View in the "Paradox"'. Social Indicators Research, 75, 241-271.

Schimmack, U. (2008) 'The Structure of Subjective Well-being' in M. Eid and R.J. Larson (eds) The Science of Subjective Well-being (New York: Guilford Press), pp. 97-123.

Sigrist, J. and M. Wahrendorf (2010) 'Social Productivity and Well-being' in L. Bovenberg, A. van Soest and A. Zaid (eds), Aging, Health and Pensions in Europe (Houndmills, Basingstoke, Hampshire: Palgrave Macmillan), pp. xxx-yyy.

Smith, J. (2002) 'The Fourth age: A Period of Psychological Mortality?' In Max-PlanckGesellschaft zur Förderung der Wissenschaften and Ernst Schering Research Foundation (eds), Biomolecular Aspects of Aging: The Social and Ethical Implications (Max-Planck-Forum No. 4) (München: Max-Planck-Gesellschaft), pp. 75-88.

Staudinger, U. (2000) 'Viele Gründe Sprechen Dagegen, und Totzdem Geht es Vielen Menschen Gut: Das Paradox des Subjektiven Wohlbefindens' [Many Reasons Speak Against it, Yet Many People Feel Good: The Paradox of Subjective Well-being], Psychologische Rundschau, 51, 185-197.

Thomae, H. (1970) 'Theory of Aging and Cognitive Theory of Personality', Human Development, 13, 1-13.

Vaarama, M. (2009) 'Care-related Quality of Life in Old Age', European Journal of Aging, 6, 113-125.

van Praag, B.M.S., P. Frijters and A. Ferrer-i-Carbonell (2003) 'The Anatomy of Subjective Well-being', Journal of Economic Behavior and Organization, 51, 29-49.

van Willigen, M. (2000) 'Differential Benefits of Volunteering across the Life Course. Journals of Gerontology, Series B: Psychological Sciences and Social Sciences, 55B, S308S318.

Watson, D., L.A. Clark and A. Tellegen (1988) 'Development and Validation of Brief Measures of Positive and Negative Affect: The PANAS Scales', Journal of Personality and Social Psychology, 54, 1063-1070.

Wheeler, J.A., K.M. Gorey and B. Greenblatt (1998) 'The Beneficial Effects of Volunteering for Older Volunteers and the People They Serve: A Meta-analysis', International Journal of Aging and Human Development, 47, 69-79. 